\title{
Phytochemicals in Wound Healing
}

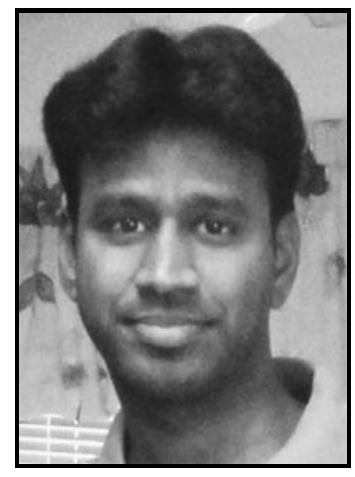

Rajesh L. Thangapazham, PhD

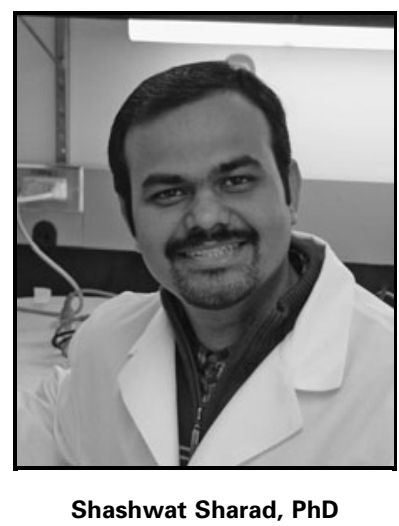

Submitted for publication September 8, 2013 Accepted in revised form March 12, 2014

${ }^{*}$ Correspondence: R. Thangapazham, Department of Dermatology, or S. Sharad, Center for Prostate Disease Research; Uniformed Services University of the Health Sciences, 4301 Jones Bridge Road, Bethesda, MD 20814 (e-mail: rajesh .thangapazham@usuhs.edu or sharadshashwat@ gmail.com).

\author{
Rajesh L. Thangapazham, ${ }^{1, *}$ Shashwat Sharad, ${ }^{2, *}$ \\ and Radha K. Maheshwari ${ }^{3}$ \\ Departments of ${ }^{1}$ Dermatology and ${ }^{3}$ Pathology; ${ }^{2}$ Department of Surgery, Center for Prostate Disease Research; \\ Uniformed Services University of the Health Sciences, Bethesda, Maryland.
}

Significance: Traditional therapies, including the use of dietary components for wound healing and skin regeneration, are very common in Asian countries such as China and India. The increasing evidence of health-protective benefits of phytochemicals, components derived from plants is generating a lot of interest, warranting further scientific evaluation and mechanistic studies.

Recent Advances: Phytochemicals are non-nutritive substances present in plants, and some of them have the potential to provide better tissue remodeling when applied on wounds and to also act as proangiogenic agents during wound healing.

Critical Issues: In this review, we briefly discuss the current understanding, important molecular targets, and mechanism of action(s) of some of the phytochemicals such as curcumin, picroliv, and arnebin-1. We also broadly review the multiple pathways that these phytochemicals regulate to enhance wound repair and skin regeneration.

Future Directions: Recent experimental data on the effects of phytochemicals on wound healing and skin regeneration establish the potential clinical utility of plant-based compounds. Additional research in order to better understand the exact mechanism and potential targets of phytochemicals in skin regeneration is needed. Human studies and clinical trials are pivotal to fully understand the benefits of phytochemicals in wound healing and skin regeneration.

\section{SCOPE AND SIGNIFICANCE}

THE MOST COMMONLY studied pathway through which phytochemicals exert their beneficial effect is nuclear factor-kappa B (NF- $\kappa \mathrm{B})$. Phytochemicals inhibit this pathway, subsequently reducing inflammation and thereby providing numerous beneficial effects. Recent studies as reviewed here are unraveling previously unidentified pathways, unique molecular targets, and novel mechanisms through which phytochemicals may perform as a therapeutic agent for wound healing and skin regeneration.

\section{TRANSLATIONAL RELEVANCE}

Phytochemicals are well known for their chemopreventive properties and are found to be beneficial in treating various disorders, including skin diseases. Phytochemicals protect the skin by quenching free radicals and reducing inflammation through the inhibition of NF- $\kappa \mathrm{B}$. Phytochemicals also affect other signaling pathways, including transforming growth factorbeta $(T G F-\beta)$ and mitogen-activated protein kinase pathway. Extensive research has increased the disease portfolio for which phytochemicals 
may be beneficial, and the identification of molecular targets will help future clinical trials in the development of phytochemicals as an important therapeutic agent.

\section{CLINICAL RELEVANCE}

Some of the challenges in the use of phytochemicals as therapeutic agents include poor solubility, bioavailability, and lack of clinical research. Poor bioavailability of phytochemicals may be due to their high intrinsic activity, poor absorption, rapid metabolism, and rapid elimination and clearance from the body. Successful elucidation of molecular targets and mechanisms of phytochemicals will lead to the development of efficacious formulations of phytochemicals, including liposomes, micelles, nanoparticles, and phospholipid complexes.

\section{INTRODUCTION}

Natural medicinal products and plant extracts have been widely used as topical applications for wound healing. ${ }^{1}$ Use of plants as a source of drug was the backbone of traditional medicine. ${ }^{2}$ Phytochemicals, naturally occurring substances found in plants, react with either oxygen groups or other biologic macromolecules to instigate biological effects and combat human diseases. ${ }^{1,3}$ Several research groups across the world have shown that phytochemicals may play a critical role in preventing and/or treating a number of deadly diseases such as cancer and inflammatory conditions ${ }^{4}$ and may also provide medicinal benefits for wound healing and skin regeneration. ${ }^{5}$ Wound healing is a complex, dynamic, and multistep process that involves several cell types, and phytochemicals have been reported to improve wound healing in different animal models (Fig. 1). ${ }^{6}$ Chronic wounds are hard to treat, and they affect millions of patients physically and, more importantly, cause mental trauma, thus reducing the quality of life drastically. ${ }^{7}$ Each wound initiates signaling pathways to regenerate the same tissue as the original one, irrespective of the wound type and degree of damage. ${ }^{8}$ Generally, the progression of wound healing involves inflammation (reactive) or exudative phase for detachment of the deteriorated tissues and wound cleansing, proliferation (regenerative) for the development of granulation tissue, and maturation (remodeling) for scar formation and epithelialization (Fig. 1). ${ }^{9}$ Usually, wound healing is rapid and usually an uncomplicated process, whereas some wounds that are associated with host impairment, such as diabetes, oxidative stress, infection, immunosuppression, or obesity, are hard to heal. ${ }^{10,11}$ Angiogenesis, also known as neovascularization, is the development of new capillaries from existing and/or pre-existing vascular networks, and it plays an integral part in

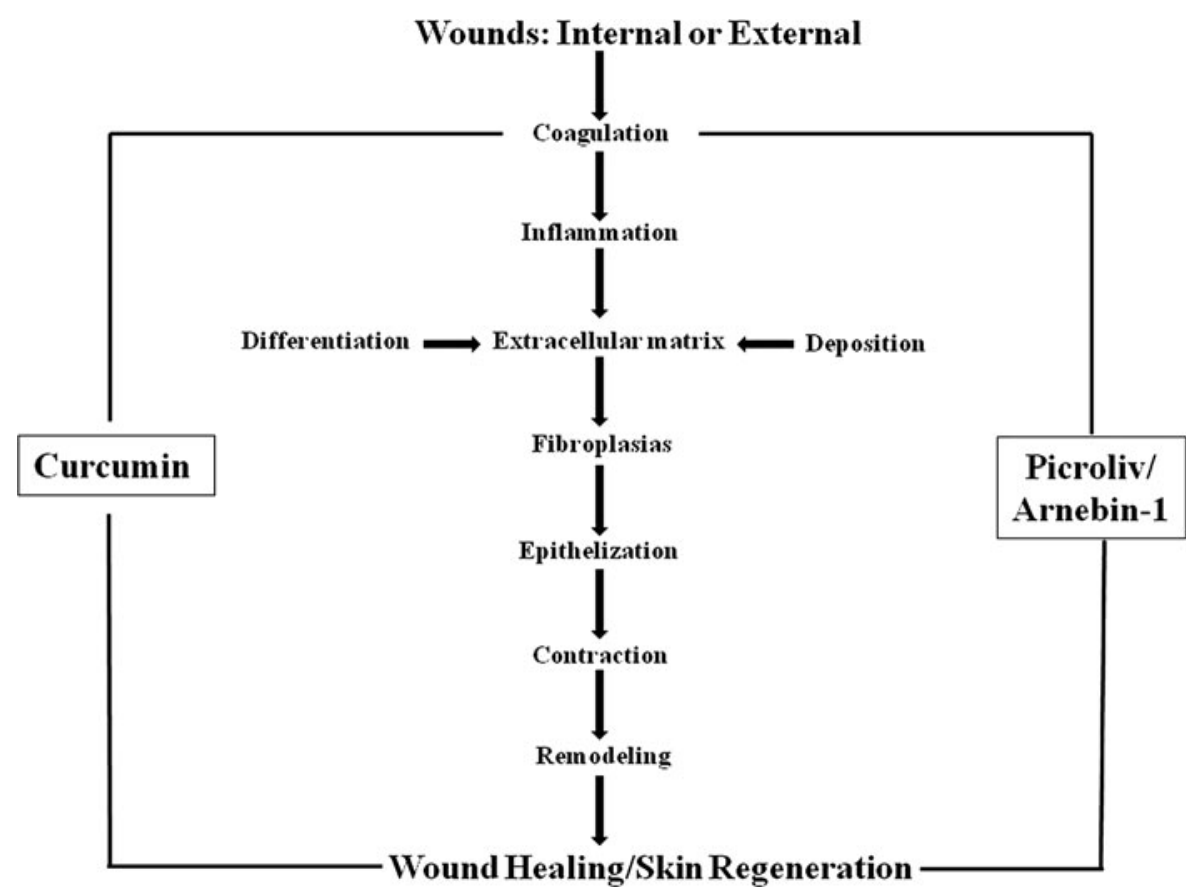

Figure 1. Schematic representation of steps involved in wound healing and potential targets of phytochemicals in wound healing and skin regeneration. 
the repair system. ${ }^{12}$ Angiogenesis is a crucial step of wound healing, and some botanical extracts have been shown to modulate angiogenesis and accelerate wound healing. ${ }^{13}$ Angiogenesis provides the nutritional supply to maintain cell metabolism and to form an intact delivery system. The regeneration (angiogenesis) occurs by forming the vascular conduits that supply nutrients, the building blocks to the cellular elements of the granulation tissue, and the overlying epidermal cells begin to migrate across the tissue defect to restore the epithelial barrier function of the skin. ${ }^{14}$ In addition, angiogenesis also helps initiate the relaxation of the cell contacts and disruption of the outer pericyte layer. ${ }^{12}$

Phytochemicals derived from plants such as curcumin consist of bioactive compounds that are traditionally used in wound healing. The increase in the use of phytochemicals as a therapeutic agent and extensive research to understand how nutrients can interact with the human genome to alter the expression of genes has led to the development of a new nutro-genomics branch of science. ${ }^{15}$ Recently, Cheppudira et al. provided a strong case for the use of curcumin for controlling severe burn pain and for improved wound healing, and they also review the analgesic and antiinflammatory effect of curcumin. ${ }^{16}$ Natural products derived from plants have medicinal uses in wound healing, and curcumin is relatively safe at higher doses. ${ }^{13}$ The administration of curcumin at the dosage of $100 \mathrm{mg} / \mathrm{kg}$ body weight showed the induction of vascularization in mice, ${ }^{17}$ whereas in mice, the down-regulation of angiogenic factors was observed after treatment with a dose of $500 \mathrm{mg} / \mathrm{kg} .{ }^{18}$ Clinical trials have demonstrated that curcuma extract can be administered safely to patients at doses of $\sim 2.2 \mathrm{~g}$ daily, equivalent to $180 \mathrm{mg}$ of curcumin. ${ }^{13}$ Dose escalation studies in patients with lesions revealed that curcumin had no treatment-related toxicity at higher doses of $\sim 8,000 \mathrm{mg} / \mathrm{kg} .{ }^{19}$ This review specifically focuses on some of the beneficial effects and molecular targets of phytochemicals such as curcumin, picroliv, and arnebin-1 in the enhancement of wound healing. Here, we discuss the possible mechanisms of action and identify the key molecular targets by which they exert protective effects. These studies will also enable us to understand the biology of wound healing (Fig. 1) and the pathogenesis of delayed wound healing. Furthermore, this review will also help us recognize the key molecular mechanisms for wound repair and skin regeneration and provide preventive strategies and effective treatment approaches.

\section{DISCUSSION \\ Curcumin}

Curcumin, a polyphenol derived from Indian dietary spice turmeric (the common name for Curcuma longa L., Zingiberaceae family), has been widely used as a herbal remedy for centuries in indigenous medicine to treat a variety of inflammatory conditions and other diseases. The active medicinal ingredient of turmeric has been identified as curcuminoids, which includes an active component curcumin (diferuloylmethane)-(1,7bis (4-hydroxy-3-methoxyphenyl)-1,6-hepadiene3,5-dione) and is found to be beneficial in treating various disorders, including skin diseases. ${ }^{9}$ The chemical structure of curcumin and its analogues are summarized in Fig. $2 .^{20-22}$ It has also been reported that curcumin possesses anti-inflammatory, antioxidant, and antiproliferative properties that are mediated through the regulation of several inflammatory cytokines, growth factors, protein kinases, transcription factors, and other enzymes. ${ }^{9}$ In addition, it has been shown that curcumin also induces apoptosis through mitochondrial and receptor-mediated pathways, as well as through activation of caspase cascades. ${ }^{23}$

\section{Curcumin in wound healing and angiogenesis}

The role of curcumin in wound healing and skin regeneration is well characterized, and curcumin has been shown to enhance wound healing in the rat and guinea pig punch model. ${ }^{10}$ Different doses of curcumin were applied either topically and/or administered orally daily to evaluate the woundhealing properties of curcumin. The dose-response studies in animals revealed that curcumin increases the wound-healing capacity at a dose of $40 \mathrm{mg} / \mathrm{kg}$ in $7-11$ days. ${ }^{10}$ It has been shown that at day 11 , the untreated wounds showed loose reticular collagen, congested vessels, and persisting inflammatory infiltrate; whereas the curcumin-treated wounds demonstrated a compact and well-aligned collagen, showing that the wound was essentially healed. ${ }^{10}$ Similarly, curcumin treatment also reduces the closure time in rats by $\sim 35 \%$ after 7 days. ${ }^{10}$

The reviews by Thangapazham et al. and Maheshwari et al. described the various biological activities of curcumin. ${ }^{9,23-25}$ It has already been shown that curcumin protects the skin by quenching free radicals and reducing inflammation through NF- $\kappa$ B inhibition. ${ }^{26,27}$ Curcumin reduces not only the wound-healing time but also improves the collagen deposition, increases fibroblast number and vascular density. ${ }^{28}$ Curcumin also acts as a pro-angiogenic agent during wound healing and wound repair by regulating $T G F-\beta .^{10-11}$ Thangapazham et al. 
<smiles>COc1cc(C=CC=CCC(=O)C=Cc2ccc(O)c(OC)c2)ccc1O</smiles>

Curcumin<smiles>CCCCCCCCCCCOc1ccc(OC)c(OC)c1</smiles>

Dim ethoxycurcumin<smiles>COc1cc(/C=C(\C(=O)/C=C/c2ccc(O)c(F)c2)C(=O)/C=C/c2ccc(O)c(OC)c2)ccc1O</smiles>

Difluorinatedcurcumin<smiles>COc1cc(/C=C/C(=O)/C=C/c2ccc(O)c(OC)c2)ccc1O</smiles>

Curcumin analogue FLL-11<smiles>COc1cc(/C=C/C(=O)/C=C/c2cc(OC)c(O)c(OC)c2)cc(OC)c1O</smiles>

Curcumin analogue FLL-12<smiles>COc1cc(/C=C/C(=O)/C=C/c2cc(OC)c(OC)c(OC)c2)cc(OC)c1OC</smiles>

Curcumin analogue G0-Y016<smiles>COCOc1cc(/C=C/C(=O)/C=C/c2cc(OCOC)cc(OCOC)c2)cc(OCO)c1</smiles>

Curcumin analogue G0-Y030<smiles>COCOc1c(OC)cc(/C=C/C(=O)/C=C/c2cc(OC)c(OCOC)c(OC)c2)cc1OC</smiles>

Curcunin analogue G0-Y031<smiles>COc1ccc(/C=C/C(=O)/C=C/c2ccc(OC)c(OC)c2)cc1OC</smiles><smiles>O=C1/C(=C/c2ccccc2F)CNC/C1=C\c1ccccc1F</smiles>

Curcumin analogue- EF24

Figure 2. Chemical structure of curcumin and its analogues. ${ }^{20-22}$

summarized the earlier findings that $T G F-\beta$ induces angiogenesis, thereby facilitating accumulation of extracellular matrix and contributing toward the remodeling phase of wound repair. ${ }^{23}$ Both Sidhu et al. and Mani et al. showed the beneficial role of curcumin in normal and impaired wound healing in various animal models. ${ }^{10-11}$ In guinea pig wound-healing animal models, faster wound closure was observed in the punch wounds treated with curcumin when compared with untreated control animals. The guinea pig punch wounds model showed that curcumin treatment resulted in a greater closure of wounds as compared with controls. At day 7, punch wounds displayed greater wound closure after curcumin treatment and showed a 2-day enhancement in wound closure as compared with the untreated group. ${ }^{10}$ Sidhu et al. observed an increase in TGF- $\beta$ and fibronectin in the curcumin-treated wounds. Based on this observation and the given fact that $T G F-\beta$ enhances wound healing, it has been implied that $T G F-\beta$ may play an important role in the enhancement of wound healing by curcumin. ${ }^{10}$ Furthermore, Mani et al. showed that along with $T G F-\beta$, nitric oxide is also an important factor in wound 
healing. ${ }^{11}$ They observed that curcumin enhances cutaneous wound healing in normal and diabetic rats treated with or without dexamethasone treatment. They also confirmed the findings of Sidhu et al. ${ }^{10}$ by showing enhanced expression of $T G F-\beta 1$ in both normal and impaired healing wounds. ${ }^{11}$ Curcumin inhibits NF- $\kappa \mathrm{B}$, which has been shown to have a potent anti-inflammatory effect, thereby expediting dermal wound healing in about 7 days. ${ }^{10,29}$ Other biological activities of curcumin and its beneficial effect in the treatment of other skin conditions have been well summarized in recent reviews. ${ }^{9,24,25}$ Kulac et al. showed the topical role of curcumin in burn wound healing using the Wistar-albino rat model. ${ }^{30}$ The thermal injury rat model was used in this study. After anesthesia, the dorsum of rats were shaved and a second-degree burn wound of a surface that was $2.5 \mathrm{~cm}$ in diameter was created by using an aluminum branding irons. The experimental rats (burn + curcumin groups) received curcumin at a concentration of $100 \mathrm{mg} / \mathrm{kg}$ body weight, topically, once daily, for a period of 12 days. ${ }^{30}$ They observed an increase in the levels of hydroxyproline in the skin of curcumintreated groups and observed much faster healing. ${ }^{30}$ They showed that topical application of curcumin accelerates the wound-healing process. The treated wounds started healing on day 4, and complete wound healing was observed on day 12 (postburn) as compared with the untreated group, which has been confirmed by histopathological and biochemical examinations. ${ }^{30}$ Their data also suggest enhanced collagen deposition, angiogenesis, granulation tissue formation, and epithelialization in curcumin-treated wounds. They also showed an increased expression of proliferating cell nuclear antigen in curcumintreated skin tissues of the burn rat group. ${ }^{30}$ Sidhu et al. demonstrated earlier re-epithelialization, increased neovascularization, and improved migration of various cells and increased deposition of collagen in curcumin-treated wounds of the genetically diabetic mice model $\left(\mathrm{C} 57 / \mathrm{Ks} \mathrm{J}-\mathrm{db}^{+} / \mathrm{db}^{+}\right.$mice), which represent spontaneous and induced forms of insulindependent diabetes mellitus. ${ }^{31}$ This diabetic mice model is very similar to the human disease and streptozotocin-induced diabetic rat models. The authors observed an increase in $T G F-\beta$ by immunohistochemical localization and mRNA expression in curcumin-treated wounds as compared with controls. The terminal deoxynucleotidyl transferase-mediated deoxyuridyl triphosphate nick end labeling analysis also showed delayed apoptosis patterns in diabetic wounds compared with curcumin-treated wounds. The most effective oral dose of $40 \mathrm{mg} / \mathrm{kg}$ body weight/ day was administered for 11 days. On the 4th day postwounding, nonviable necrotic areas and inflam- matory cells were visible in the wound of untreated rodents, whereas curcumin-treated wounds showed an increase in the infiltration of cells and enhanced neovascularization. By the 7th day, migration of the epithelium over the dermis was observed along with the granulation tissue formation, including neovascularization in curcumin-treated wounds. A complete re-epithelialization of the wound was observed in curcumin-treated wounds on the 11th day as compared with the untreated group. ${ }^{31}$ The curcumintreated wounds of streptozotocin-induced diabetic rats showed an increase in the epithelial migration and a decrease in the wound gap and width, suggesting that curcumin treatment resulted in enhanced wound closure in these healing-impaired animal models. Similarly, wounds in $\mathrm{db}^{+} / \mathrm{db}^{+}$mice treated orally or topically with curcumin studied at the 7th and 11th day postwounding showed enhanced migration of the epithelium in curcumintreated wounds of genetically diabetic mice compared with diabetic rats on the 7 th day. By day 11 , vessel density was reduced to a larger extent in the treated wounds and was even slightly lower than in the control wounds, which correlated with the better collagenization of curcumin-treated wounds, suggesting better wound organization with early regression of granulation tissue with curcumin treatment. ${ }^{31}$ These results showed that curcumin can enhance wound repair in the diabetic-impaired wound healing animal model, and it may be developed as a safe pharmacological agent for use in clinics. $^{31}$

Panchatcharam et al. demonstrated the effect of curcumin on collagen synthesis and its antioxidant effects during cutaneous wound healing in male albino Wistar strain rats. ${ }^{32}$ Curcumin was topically administered to full-thickness excision wounds that were created on the back of the rat. Wound tissues collected at various time points (4th, 8th, and 12th day postwounding) revealed that curcumin increases the cellular proliferation and collagen synthesis at the wound site as seen by the increase in DNA, total protein, and type III collagen content of wound tissues. The histopathological evaluation confirmed that curcumin-treated wounds heal much faster and better as indicated by improved rates of epithelialization and increased tensile strength, respectively. ${ }^{32}$ They observed that curcumin increased cellular proliferation and collagen synthesis at the wound site and accelerated the healing process by re-establishing the damaged tissue at day 4 and by day 12, orderly progression of the damaged tissue was observed. Curcumin-treated wounds were found to heal much faster, and better maturation and cross-linking of collagen 
were observed in the curcumin-treated rats, by increased stability of acid-soluble collagen, aldehyde content, shrinkage temperature, and tensile strength at day 12 as compared with control groups. ${ }^{32}$ They also show that curcumin treatment not only decreases the levels of lipid peroxides significantly but also increases the levels of superoxide dismutase, catalase, and glutathione peroxidase activities, which confirm the antioxidant properties of curcumin and its beneficial effects in accelerating wound healing. ${ }^{32}$

Curcumin has the potential mechanisms to enhance wound healing by activating the antiinflammatory and reactive oxygen species in the wound bed. Sharma et al. examined the molecular mechanism of curcumin in a preventive and therapeutic model of indomethacin-induced gastric ulceration with regard to angiogenic processes. ${ }^{33}$ Impaired blood vessels, dwindled collagen matrices, and trivial injury to mucosal cells were observed during ulceration. They showed that curcumin can block the ulceration by inducing collagenization and angiogenesis in gastric tissues via up-regulation of matrix metalloproteinase-2 (MMP-2), membrane type 1-MMP, vascular endothelial growth factor $(V E G F)$, and $T G F-\beta$ in blood vessels. By inducing these angiogenic modulators, curcumin stimulates vascular sprout formation and collagen fiber restoration in ulcerated tissues. This demonstrates curcumin-mediated faster healing and remodeling of gastric tissues by restoring the collagen architecture and accelerating angiogenesis. ${ }^{33}$ The curcumin-treated wounds were found to contract much faster. The epithelialization period of the treated wounds showed a significant decrease from 23 to 11 days. ${ }^{33}$ Similarly, a marked difference was observed in the tensile strength of tissues from the control and experimental incision wounds. A significant increase of $129 \%$ in tensile strength was observed on the 8th day in curcumin-treated groups. Furthermore, this study also substantiates that the topical administration of curcumin was found to improve all the phases of wound repair, including collagen synthesis and maturation, wound contraction, and epithelialization. ${ }^{33}$

Furthermore, several other investigators also showed that curcumin accelerates the healing of gastric ulcers by reepithelialization, by demonstrating glutathione depletion, lipid peroxidation, and protein oxidation. ${ }^{28,34,35}$ Enhanced cell proliferation and an increase in free radicals was also observed in curcumin treatment, which reduces the wound of ulcers. ${ }^{35}$ Curcumin integrates in the wound matrix and increases the higher thermostability of collagen in the wound. It has also been shown that curcumin has the potential to reverse the damage of keratinocytes, skin cells, and fibroblasts from oxidative damage. ${ }^{35}$

Curcumin also suppresses the early growth response-1 gene (Egr-1), the key regulator of various genes involved in vasculature and wound healing. ${ }^{36}$ By suppressing Egr-1, curcumin can suppress the thrombogenic events associated with various pathological conditions in endothelial cells and fibroblasts. ${ }^{37} \mathrm{Gu}$ et al. showed that radiationexposed wounds result in severe inhibition of inflammatory response. They also observed the very slow maturation of granulation tissue, reduced collagen and hexosamine synthesis, and delayed re-epithelialization. ${ }^{38}$ Jagetia and Rajanikant showed that the curcumin pretreatment before irradiation can enhance the synthesis of collagen, hexosamine, DNA, and nitrate, resulting in reduced wound healing time, improved collagen deposition, increase in fibroblasts, vascular density, and increase in the contraction of irradiated wounds. ${ }^{39-41}$ A full-thickness skin wound was produced on the dorsum of Swiss albino mice treated with and without $25,50,100,150$, or $200 \mathrm{mg} / \mathrm{kg}$ body weight of curcumin before exposure to 6 Gy gamma radiations. ${ }^{40}$ The progression of wound contraction was monitored using video images of the wound at various days postirradiation until full healing occurred. Mean woundhealing times were also calculated. Irradiation caused a significant delay in wound contraction and healing times. However, treatment with curcumin resulted in a dose-dependent increase in contraction when compared with a control. Complete healing was achieved by day 23 postirradiation in the curcumin-treated irradiation group, ${ }^{40}$ as compared with the control group. Therefore, curcumin can be effectively used in the treatment of irradiated wounds for improving the delayed healing.

Several clinical trials have shown that curcumin is safe even at high doses ( $12 \mathrm{~g} /$ day) in humans but exhibits poor bioavailability. ${ }^{42}$ Major reasons contributing to the low plasma and tissue levels of curcumin appear to be due to poor absorption, rapid metabolism, and rapid systemic elimination. To improve the bioavailability of curcumin, numerous approaches have been undertaken. These approaches involve (1) the use of adjuvants such as piperine that interferes with glucuronidation, (2) the use of liposomal curcumin, (3) curcumin nanoparticles, (4) the use of curcumin phospholipid complex, and (5) the use of structural analogues of curcumin (e.g., EF-24). ${ }^{42}$ Currently, studies on curcumin are mainly focused on developing novel 
formulations to improve the delivery and increase the bioavailability of curcumin. Recently, Gadekar and his colleagues showed that curcumin patches formulation can be used as a transdermal therapeutic system for wound healing. ${ }^{43}$ They used poly vinyl pyrrolidone and ethyl cellulose to enhance the permeation of curcumin patch. By this method, they showed that curcumin effectively passes into the systemic circulation through the skin by a diffusion-controlled mechanism in the albino rat wound-healing model. After treatment with curcumin, enhanced contraction rate and healing time of wounds were observed in the form of an organized epidermis, due to an increase in epithelialization. After 9 days of curcumin patch treatment, wounds exhibit distinct dryness of wound margins with tissue regeneration. The treated group showed better wound closure as compared with control animals. They showed an enhanced rate of wound contraction and a drastic reduction in healing time than the control. The curcumin patchtreated group showed $90 \%$ wound contraction in 8 days and about $100 \%$ in 10 days as compared with controls, where $90 \%$ wound contraction was observed in 21 days. ${ }^{43}$ The histopathological analysis of these animals demonstrated a well-organized collagen fiber increase in fibroblast cells and the formation of new blood vessels. ${ }^{44}$ This study highlighted that wound healing and wound repair are accelerated by curcumin patch formulation in albino rat models. In addition, Chereddy et al. formulated curcumin in poly (lactic-co-glycolic acid) nanoparticles and demonstrated higher reepithelialization, granulation tissue formation, and anti-inflammatory potential of curcumin in the full-thickness excisional wound-healing mouse model. ${ }^{45}$ They also showed protection from light degradation, enhanced water solubility, and a sustained release of curcumin due to their novel formulation. ${ }^{45}$ Gong et al. prepared a biodegradable thermosensitive hydrogel formulation of curcumin and showed enhancement of wound healing in their formulation. ${ }^{46}$ These studies summarize that treatment with curcumin increases the rate of re-epithelialization of the epidermis, migration of myofibroblasts, increases fibroblast and macrophage numbers in the wound bed, and improves neovascularization and collagen deposition. Recently, Heng showed that topical application of curcumin delivered as a gel preparation leads to perfect skin regeneration and results in minimal residual scarring in patients treated for squamous cell carcinoma and sclerosing basal cell carcinoma. ${ }^{47}$ These studies show that curcumin can be effectively used therapeutically for enhancing wound healing. Novel formulations of curcumin, including nanocrystal solid dispersion, amorphous solid dispersion, and nano emulsion, are being developed to overcome the challenges and limitations of poor solubility, bioavailability, and photostability of the compound. Other formulations such as liposomes, micelles, nanoparticles, and phospholipid complexes that provide longer circulation and better permeability are also being used. ${ }^{42,48}$ These novel delivery systems enhance the stability, bioavailability, and cellular uptake of curcumin and other phytochemicals. ${ }^{43,44}$

\section{Picroliv}

Picroliv is a standardized fraction derived from the roots and rhizomes of the plant Picrorhiza kurroa (commonly called katuka, kutki, kurro, or kutaki). The major active component of picroliv consists of iridoid glycosides, picroside-1, and kutkoside in a ratio of $1: 1.5 \mathrm{w} / \mathrm{w}$. It is traditionally used to treat various diseases such as fever, asthma, allergies, hepatitis, and other inflammatory conditions. ${ }^{44-46,48}$ The chemical structure of picroliv and its constituents are provided in Fig. $3{ }^{49,50}$

\section{Picroliv in wound healing and angiogenesis}

Singh et al. investigated the effect and role of picroliv in an ex vivo rat aorta ring model of angiogenesis and punch wound healing. Picroliv treatment not only enhanced the sprouting and migration of endothelial cells but also showed improved re-epithelialization, neovascularization, and migration of various cells such as endothelial, dermal myofibroblasts and fibroblasts into the wound bed. ${ }^{49}$ In rats, picroliv also up-regulated the expression of $V E G F$ in human umbilical vein endothelial cells and insulin-like growth factor during hypoxia. ${ }^{51}$ The exact mechanism of action of the therapeutic action of picroliv is unclear. However, increased $V E G F$, consistent with an increased number of microvessels and increased myo fibroblasts in granulation tissue, may be some of the targets of picroliv. The picroliv were administered daily to male Sprague-Dawley rats at a dose of $12 \mathrm{mg} / \mathrm{kg}$ body weight. Picroliv treatment resulted in improved re-epithelialization, neovascularization, and migration of various cells into the wound bed within the 4 th day of treatment, and complete wound healing was attained within the 7th day of treatment; whereas in untreated controls groups, wounds did not heal within 7 days. These results suggest that picroliv can be developed and used as a therapeutic wound-healing and angiogenic agent for the restoration of the blood supply in diseases 


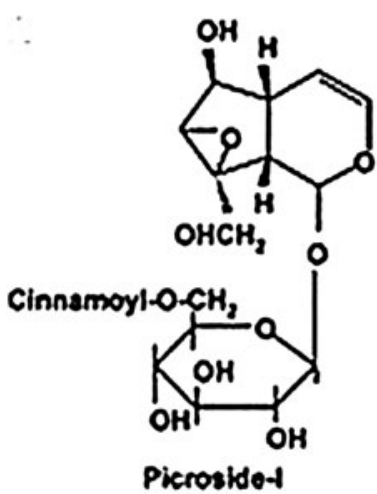

Picroliv

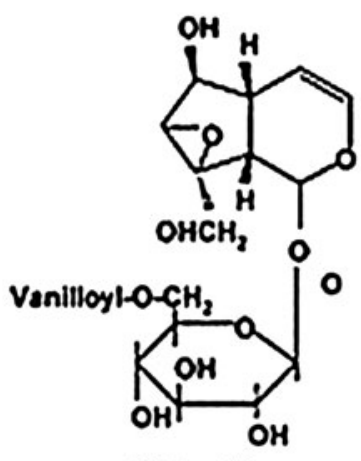

Kutkosido

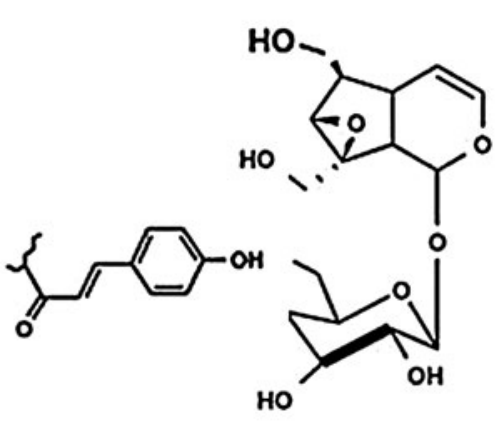

PicrosideI

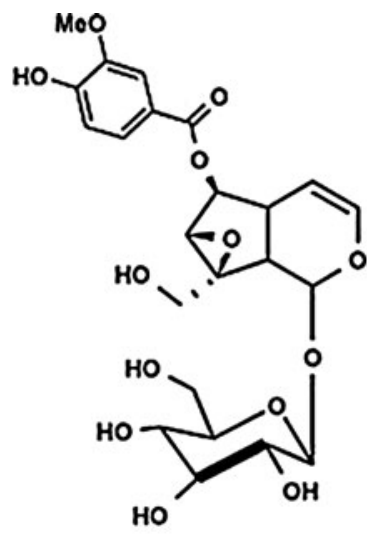

PicrosideII

Figure 3. Chemical structure of picroliv and its constituents. ${ }^{49,50}$

involving inadequate blood supply such as delayed wound healing. ${ }^{48}$

\section{Arnebin-1}

Arnebin-1 is one of the naphthaquinones derivative derived from the plant root of Arnebia nobilis (a member of Boraginaceae genus). The root extract was widely used in traditional medicine in India for wound healing. ${ }^{52}$ The chemical structure of arnebin-1 (5,8-dihydroxy-2-(1'-b,b-dimethylaroxy $-4^{\prime}$-methylpent-3-enyl)-1 is shown in Fig. $4 .^{53}$

\section{Arnebin-1 in wound healing}

Several biological activities such as wound healing, anti-bacterial, anti-fungal, and anti-cancer effects of arnebin-1 have been previously shown. ${ }^{20,53,54}$ Sidhu et al. evaluated the effect of arnebin-1 on normal and impaired wound healing in the cutaneous punch wound rat model. ${ }^{52}$ Topical applica-

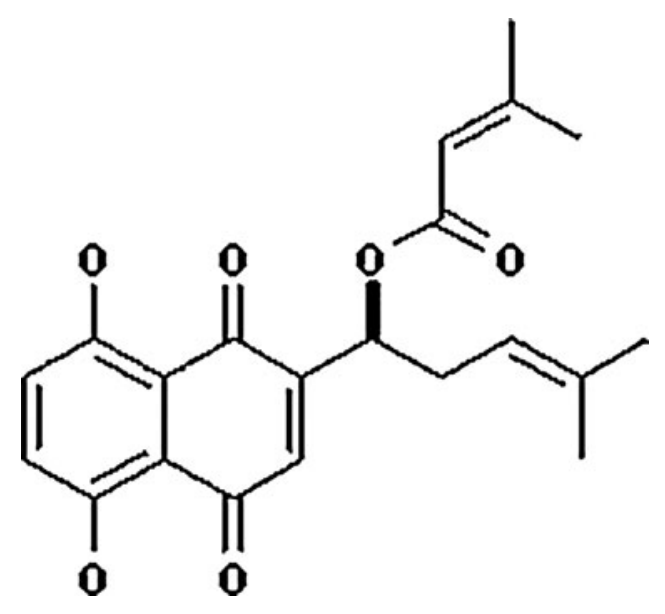

Figure 4. Chemical structure of Arnebin-1 $\left[\mathrm{C}_{21} \mathrm{H}_{22} \mathrm{O}_{6}\right] .{ }^{53}$ tion of arnebin-1 was performed daily on wounds of hydrocortisone-treated or untreated male SpragueDawley rats for 11 days. They demonstrated that arnebin-1 significantly accelerated the woundhealing process with or without hydrocortisone treatment. Arnebin-1 (0.1\% aqueous suspension in phosphate-buffered saline) was applied on the day of wounding and from then onward daily for 11 days, whereas the vehicle control animals received PBS on their wounds. Wounds treated with arnebin-1 showed a statistically significant decrease in the epidermal gap between the migrating tongues of epidermis as compared with vehicle control and hydrocortisone-treated wounds. ${ }^{52}$ The increase in the re-epithelialization was also observed in wounds treated for 7 days, and the rate of gap closure was slightly accelerated over that observed at day 4 . The rate of re-epithelialization in hydrocortisone-treated wounds, however, was slower as compared with control wounds. Contraction (width) of the wounds was also evaluated at both 4 and 7 days. After 4 days of arnebin- 1 treatment, wounds showed a statistically significant difference in the decrease of wound width in both normal and hydrocortisone-treated wounds as compared with controls. The decrease in the wound width was also observed at day 7 . These data demonstrate that arnebin-1 treatment increases wound re-epithelialization and contraction, suggesting that arnebin-1 enhanced wound closure in both normal and healing-impaired animals. ${ }^{52}$ They also observed a significant reduction in the wound width and gap length as compared with controls. It has also been reported that arnebin-1 treatment can induce cell proliferation, migration, and vessel formation to form a thick granulation tissue and 
re-epithelialization of the wounds. ${ }^{52}$ The increase in the synthesis of collagen, fibronectin, and TGF-1 was also reported by Sidhu et al. in arnebin-1treated wounds compared with the untreated control. $^{52}$ They suggested that arnebin-1 could possibly enhance the expression of TGF-1 at both translational and transcriptional level, which might be responsible for the enhancement of wound healing. ${ }^{55}$ Taken together, these findings suggest that arnebin-1 has the potential to be further studied as a potent therapeutic agent for wound healing.

\section{CONCLUSION}

We have summarized the preclinical and experimental studies suggesting the beneficial nature of curcumin and other phytochemicals in wound healing and skin regeneration. In conclu- sion, the approach of using phytochemicals such as curcumin, picroliv, and arnebin-1 for the treatment of wound healing shows potential. Phytochemicals not only look promising but are also a cost-effective treatment modality. These findings highlight the fact that phytochemicals could be developed as a therapeutic tissue remodeling and angiogenic agent for wound repair and the restoration of the blood supply in skin diseases, especially in wound healing. Based on these studies reviewed here, we propose a model representing the role of phytochemicals in early wound closure and the effect of curcumin, picroliv, and arnebin-1 in wound healing and angiogenesis with proposed molecular target(s) (Fig. 5). The basic goal of wound healing is to facilitate wound closure and restore barrier function of the skin. This event is highly conserved and involves multiple processes such as inflammation and epithelialization orchestrated by many

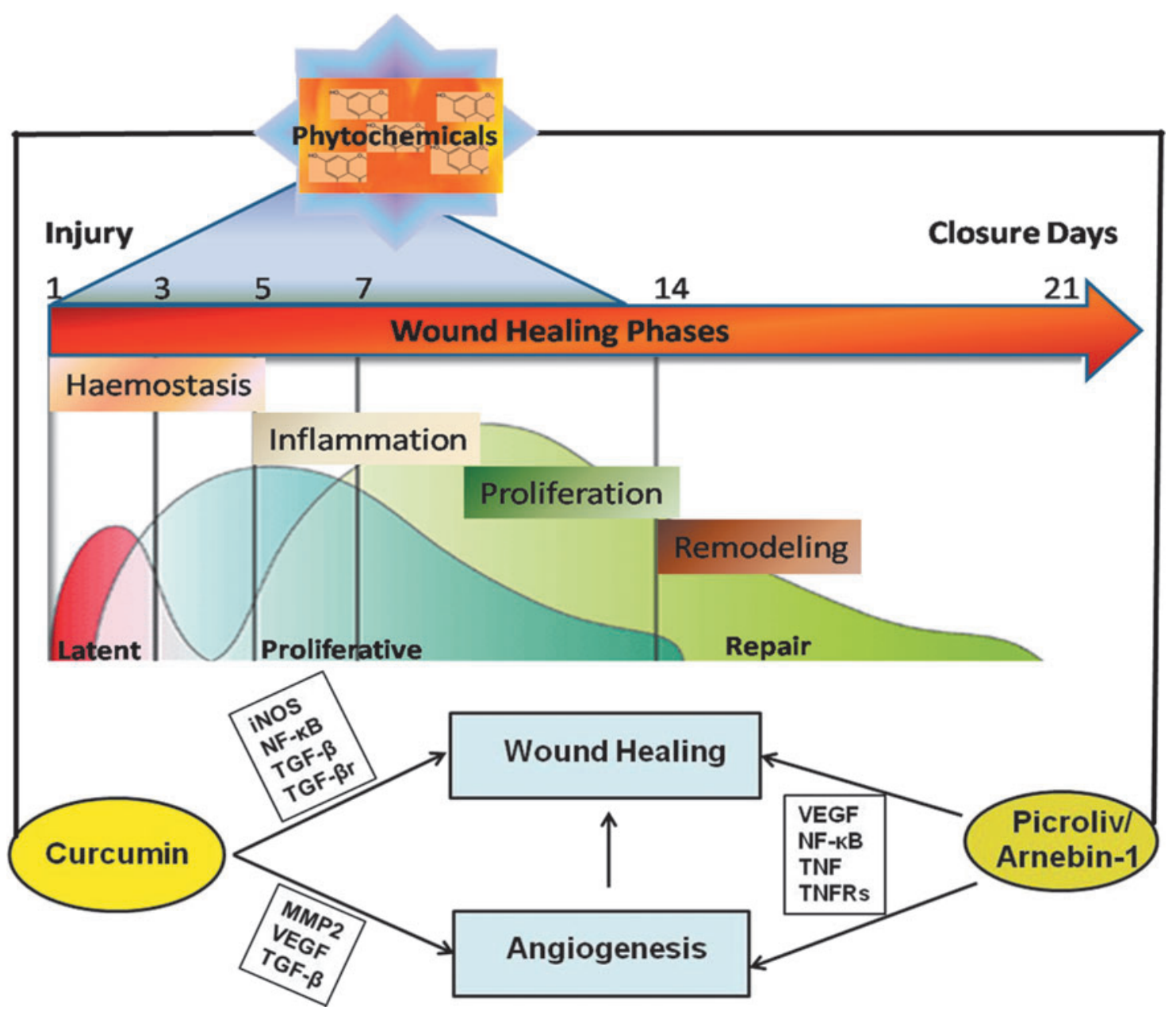

Figure 5. Schematic representation of the role of phytochemicals in early wound closure and the effect of curcumin, picroliv, and arnebin-1 in wound healing and angiogenesis with proposed molecular target(s). iNOS, inducible nitric oxide synthase; MMP-2, matrix metalloproteinase-2; NF- $\kappa$, nuclear factor-kappa B; TGF- $\beta$, transforming growth factor-beta; TNF, tumor necrosis factor; TNFR, TNF receptor; VEGF, vascular endothelial growth factor. To see this illustration in color, the reader is referred to the web version of this article at www.liebertpub.com/wound 
different cell types. To co-ordinate these complex signaling pathways and remodel the wound environment, various cellular components secrete matrix proteins and bioactive molecules. The most commonly studied targets through which phytochemicals exert their beneficial effects in wound healing and angiogenesis are NF$\kappa \mathrm{B}$, TGF- $\beta$, VEGF, tumor necrosis factor (TNF), and inducible nitric oxide synthase (iNOS) (Fig. 5). The model in Fig. 5 identifies the specific modulation of these targets by phytochemicals reviewed in this study and proposes a model for the wound healing and phytochemicals. Recent studies as reviewed here unravel the previously unidentified pathways, unique molecular targets, and novel mechanisms through which phytochemicals may perform skin restoration during the wound-healing process. We believe that continuous research will lead to clinical development of phytochemicals as a beneficial agent for wound healing and angiogenesis. Although phytochemicals have been widely investigated in skin regeneration research, there is a lack of randomized controlled trials investigating both the effectiveness and the side effects of these compounds.

\section{ACKNOWLEDGMENTS AND FUNDING SOURCES}

Some of this work was supported by an intramural grant from the US Military Cancer Institute, Uniformed Services University of the Health Science, Bethesda, US-INDIA Foreign Currency Fund from US Department of State to USUHS. The opinions or assertions contained here are the private views of the authors and should not be construed as official or necessarily reflecting the views of the Uniformed Services University of the Health Sciences or the Department of Defense, USA.

\section{AUTHOR DISCLOSURE AND GHOSTWRITING}

The authors declare that no competing financial interests exist. No ghostwriters were used to write this article.

\section{ABOUT THE AUTHORS}

Rajesh L. Thangapazham, $\mathbf{P h D}$, is a Senior Research Associate in Dermatology at Uniformed Services University of Health Sciences. His main focus is to develop preclinical studies for cancer chemoprevention and skin regeneration. Currently he works on tumorigenesis, skin regeneration, and wound healing. He established a novel animal and cell culture model to study molecular mecha$\operatorname{nism}(\mathrm{s})$ of skin and organ regeneration with special focus on hair follicles. Shashwat Sharad, PhD, is a postdoctoral fellow at the Center for Prostate Disease Research. Initially he worked on genes involved in neuropsychiatric disorders and the role of Ayurvedic Medicine in Metabolic Syndrome. Currently he is focusing on exploring the role of DNA methylation with respect to the androgen receptor and the loss of androgen-regulated genes PMEPA1 and ERG in prostate cancer progression. Radha K. Maheshwari, PhD, is a Professor of Pathology at the Uniformed Services University of the Health Sciences. His research interests include the biology of interferon systems against membrane viruses; the role of interferons/cytokines in malaria, Leishmania, and fungal infections; mechanisms of regulation of cytokines/growth factors by novel pharmacologic agents in the enhancement of wound healing and tissue repair; prevention of hemorrhage-induced injury; the role of phytochemicals in angiogenesis in chemoprevention of cancer; and the mechanisms of pathogenesis, biomarker, and vaccine development. 


\section{REFERENCES}

1. Hsu S: Green tea and the skin. J Am Acad Dermatol 2005; 52: 1049

2. Farnsworth NR: Ethnopharmacology and drug discovery. Proceedings of Ciba foundation symposium. Chinchester: Wiley 1994, Vol. 185, pp. 42-59.

3. Sharma RA, Gescher AJ, and Steward WP: Curcumin: the story so far. Eur J Cancer 2005; 41 1955

4. Bhattacharjee S and Mandal DP: Angiogenesis modulation-the "spice effect." J Environ Pathol Toxicol Oncol 2012; 31: 273

5. Vanden Berghe W and Haegeman G: Epigenetic remedies by dietary phytochemicals against inflammatory skin disorders: myth or reality? Curr Drug Metab 2010; 11: 436.

6. Mohanty C, Das M, and Sahoo SK: Sustained wound healing activity of curcumin loaded oleic acid based polymeric bandage in a rat model. Mol Pharm 2012; 9: 2801

7. Chandan KS, Gayle MG, Sashwati R, et al:: Human skin wounds: a major and snowballing threat to public health and the economy. Wound Repair Regen 2009; 17: 763.

8. Aukhil I: Biology of wound healing. Periodontol 2000; 22: 44.

9. Thangapazham RL, Sharad S, and Maheshwari RK: Skin regenerative potentials of curcumin. Biofactors 2013; 39: 141.

10. Sidhu GS, Singh AK, Thaloor D, et al:: Enhancement of wound healing by curcumin in animals. Wound Repair Regen 1998; 6: 167.

11. Mani H, Sidhu GS, Kumari R, Gaddipati JP, Seth P, and Maheshwari RK: Curcumin differentially regulates TGF-beta1, its receptors and nitric oxide synthase during impaired wound healing. Biofactors 2002; 16: 29

12. Robson MC, Steed DL, and Franz MG: Wound healing: biologic features and approaches to maximize healing trajectories. Curr Probl Surg 2001; 38: 72

13. Majewska I and Gendaszewska-Darmach E: Proangiogenic activity of plant extracts in accelerating wound healing - a new face of old phytomedicines. Acta Biochim Pol 2011; 58: 449

14. Iocono JA, Ehrlich HP, Gottrup F, and Leaper DJ: The biology of healing. In: Wounds: Biology and Management, edited by Leaper DJ and KG Harding. Oxford, United Kingdom: Oxford University Press, 1998, pp. 4-15.

15. Reszka E, Wasowicz W, and Gromadzinska J: Genetic polymorphism of xenobiotic metabolising enzymes, diet and cancer susceptibility. Br J Nutr 2006; 96: 609.

16. Cheppudira B, Fowler M, McGhee L, et al:: Curcumin: a novel therapeutic for burn pain and wound healing. Expert Opin Invest Drugs 2013; 22 1295.

17. Jagetia GC and Rajanikant GK: Acceleration of wound repair by curcumin in the excision wound of mice exposed to different doses of fractionated $\gamma$ radiation. Int Wound J 2012; 9: 76.

18. Lin $Y G$, Kunnumakkara $A B$, Nair $A$, et al.: Curcumin inhibits tumor growth and angiogenesis in ovarian carcinoma by targeting the nuclear factor-kappaB pathway. Clin Cancer Res 2007; 13: 3423

19. Cheng AL, Hsu CH, Lin JK, et al.: Phase I clinical trial of curcumin, a chemopreventive agent, in patients with high-risk or pre-malignant lesions. Anticancer Res 2001; 21: 2895.

20. Ohori $H$, Yamakoshi $H$, Tomizawa $M$, et al.: Synthesis and biological analysis of new curcumin analogues bearing an enhanced potential for the medicinal treatment of cancer. Mol Cancer Ther 2006; 5: 2563.

21. Cen L, Hutzen B, Ball S, et al:: New structural analogues of curcumin exhibit potent growth suppressive activity in human colorectal carcinoma cells. BMC Cancer 2009; 9: 99.

22. Mimeault M and Batra SK: Potential applications of curcumin and its novel synthetic analogs and nanotechnology-based formulations in cancer prevention and therapy. Chin Med 2011; 6: 31

23. Thangapazham RL, Sharma A, and Maheshwari RK: Beneficial role of curcumin in skin diseases. Adv Exp Med Biol 2007; 595: 343

24. Thangapazham RL, Sharma A, and Maheshwari RK: Multiple molecular targets in cancer chemoprevention by curcumin. AAPS J 2006; 8: 443.

25. Maheshwari RK, Singh AK, Gaddipati J, and Srimal RC: Multiple biological activities of curcumin: a short review. Life Sci 2006; 78: 2081.

26. Chun KS, Keum YS, Han SS, Song YS, Kim SH, and Surh YJ: Curcumin inhibits phorbol esterinduced expression of cyclooxygenase-2 in mouse skin through suppression of extracellular signal-regulated kinase activity and NFkappaB activation. Carcinogenesis 2003; 24 1515.

27. Grandjean-Laquerriere A, Gangloff SC, Le Naour R, Trentesaux C, Hornebeck W, and Guenounou $\mathrm{M}$ : Relative contribution of NF-kappaB and AP-1 in the modulation by curcumin and pyrrolidine dithiocarbamate of the UVB-induced cytokine expression by keratinocytes. Cytokine 2002; 18 168.

28. Gopinath D, Ahmed MR, Gomathi K, Chitra K, Sehgal PK, and Jayakumar R: Dermal wound healing processes with curcumin incorporated collagen films. Biomaterials 2004; 25: 1911.

29. Shehzad A, Rehman G, and Lee YS: Curcumin in inflammatory diseases. Biofactors 2013; 39: 69.
30. Kulac M, Aktas C, Tulubas F, et al:: The effects of topical treatment with curcumin on burn wound healing in rats. J Mol Histol 2013; 44: 83.

31. Sidhu GS, Mani H, Gaddipati JP, et al:: Curcumin enhances wound healing in streptozotocin induced diabetic rats and genetically diabetic mice. Wound Repair Regen 1999; 7: 362.

32. Panchatcharam M, Miriyala S, Gayathri VS, and Suguna L: Curcumin improves wound healing by modulating collagen and decreasing reactive oxygen species. Mol Cell Biochem 2006; 290: 87.

33. Sharma AV, Ganguly K, Paul S, Maulik N, and Swarnakar S: Curcumin heals indomethacininduced gastric ulceration by stimulation of angiogenesis and restitution of collagen fibers via VEGF and MMP-2 mediated signaling. Antioxid Redox Signal 2012; 16: 351

34. Swarnakar S, Ganguly K, Kundu P, Banerjee A Maity $P$, and Sharma AV: Curcumin regulates expression and activity of matrix metalloproteinases-9 and -2 during prevention and healing of indomethacin-induced gastric ulcer. J Biol Chem 2005; 280: 9409 .

35. Phan TT, See PS, Lee T, and Chan SY: Protective effects of curcumin against oxidative damage on skin cells in vitro: Its implication for wound healing. J Trauma 2001; 51: 927.

36. Khachigian LM, Lindner V, Williams AJ, and Collins T: Egr-1-induced endothelial gene expression: a common theme in vascular injury. Science 1997; 271: 1427.

37. Pendurthi UR and Rao LV: Suppression of transcription factor Egr-1 by curcumin. Thromb Res 2000; 97: 179 .

38. Gu Q, Wang D, Cui C, Gao Y, Xia G, and Cui X Effects of radiation on wound healing. $J$ Environ Pathol Toxicol Oncol 1998; 17: 117.

39. Jagetia GC and Rajanikant GK: Curcumin treatment enhances the repair and regeneration of wounds in mice exposed to hemibody gammairradiation. Plast Reconstr Surg 2005; 115: 515.

40. Jagetia GC and Rajanikant GK: Effect of curcumin on radiation-impaired healing of excisional wounds in mice. J Wound Care 2004; 13: 107

41. Jagetia GC and Rajanikant GK: Role of curcumin, a naturally occurring phenolic compound of turmeric in accelerating the repair of excisionwound, in mice whole-body exposed to various doses of gamma-radiation. J Surg Res 2004; 120: 127.

42. Anand $P$, Kunnumakkara $A B$, Newman $R A$, and Aggarwal BB. Bioavailability of curcumin: problems and promises. Mol Pharmaceutics 2007; 4: 807.

43. Gadekar R, Saurabh MK, Thakur GS, and Saurabh A: Study of formulation, characterization and wound healing potential of transdermal patches of curcumin. Asian J Pharm Clin Res 2012; 5 (Suppl 4): 225. 
44. Anand P, Kunnumakkara AB, Harikumar KB, Ahn KS, Badmaev V, and Aggarwal BB. Modification of cysteine residue in $\mathrm{p} 65$ subunit of nuclear factorkappaB (NF-kappaB) by picroliv suppresses NFkappaB-regulated gene products and potentiates apoptosis. Cancer Res 2008; 68: 8861.

45. Chereddy KK, Coco R, Memvanga PB, et al:: Combined effect of PLGA and curcumin on wound healing activity. J Control Release 2013; 171: 208.

46. Gong C, Wu 0 , Wang $Y$, et al:: A biodegradable hydrogel system containing curcumin encapsulated in micelles for cutaneous wound healing. Biomaterials 2013; 34: 6377.

47. Heng MC: Wound healing in adult skin: aiming for perfect regeneration. Int J Dermatol 2011; 50: 1058.

48. Basnet $\mathrm{P}$ and Skalko-Basnet N: Curcumin: an antiinflammatory molecule from a curry spice on the path to cancer treatment. Molecules 2011; 16: 4567.
49. Kui Zhang, Jian-Jie Yu, Yu-Min Li, et al:: A Picrorhiza kurroa derivative, picroliv, attenuates the development of dextran-sulfate-sodium-induced colitis in mice. Mediators Inflamm 2012; 2012: 751629 .

50. Sampath KHM, Singh PP, Pal P, et al:: Development of novel lipidated analogs of picroside as vaccine adjuvants: acylated analogs of picroside-II elicit strong Th1 and Th2 response to ovalbumin in mice. Vaccine 2010; 28: 8327.

51. Singh AK, Sharma A, Warren J, et al:: Picroliv accelerates epithelialization and angiogenesis in rat wounds. Planta Med 2007; 73: 251.

52. Sidhu GS, Singh AK, Banaudha KK, Gaddipati JP, Patnaik GK, and Maheshwari RK: Arnebin-1 accelerates normal and hydrocortisone-induced impaired wound healing. J Invest Dermatol 1999; 113: 773
53. Shukla YN, Tandon JS, Bhakun DS, and Dhar MM: Naphthaquinones of Arnebin nobilis. Phytochemistry 1971; 10B: 109.

54. Katti SB, Shukla YN, and Tandon JS: Arnebin derivatives for anti-cancer activity. Indian $\mathrm{J}$ Chem 1979; 18B: 440.

55. Painuly P, Katt SB, Bajpai SK, and Tandon JS: Studies of metal (II and III) complexes of Arnebin1. Indain J Chem 1984; 23A: 166.

\section{Abbreviations and Acronyms}

Egr-1 $=$ early growth response- 1 gene MMP-2 = matrix metalloproteinase-2

$\mathrm{NF}-\kappa \mathrm{B}=$ nuclear factor-kappa $\mathrm{B}$

TGF- $\beta=$ transforming growth factor-beta

$\mathrm{TNF}=$ tumor necrosis factor

$\mathrm{VEGF}=$ vascular endothelial growth factor 